\begin{tabular}{|l|l|l||}
\hline \multicolumn{2}{|c|}{ PublisherInfo } \\
\hline \hline PublisherName & $:$ & BioMed Central \\
\hline \hline PublisherLocation & $:$ & London \\
\hline \hline PublisherImprintName & $:$ & BioMed Central \\
\hline \hline
\end{tabular}

\title{
PTEN Immunohistochemistry in Breast Carcinoma
}

\begin{tabular}{|l|l|l||}
\hline \multicolumn{2}{|c||}{ ArticleInfo } \\
\hline \hline ArticleID & $:$ & 3641 \\
\hline \hline ArticleDOI & $:$ & $10.1186 /$ bcr-1999-66619 \\
\hline \hline ArticleCitationID & $:$ & 66619 \\
\hline \hline ArticleSequenceNumber & $:$ & 61 \\
\hline \hline ArticleCategory & $:$ & Paper Report \\
\hline ArticleFirstPage & $:$ & 1 \\
\hline \hline ArticleLastPage & $:$ & 4 \\
\hline \hline & & RegistrationDate : 1999-11-1 \\
\hline ArticleHistory & $:$ & OnlineDate \\
\hline \hline ArticleCopyright & $:$ & Current Science Ltd1999-11-1 \\
\hline \hline ArticleGrants & $:$ & \\
\hline \hline ArticleContext & $:$ & 1305811 \\
\hline \hline
\end{tabular}




\section{Keywords}

Breast carcinoma, immunohistochemistry, loss of heterozygosity, PTEN, 10q23

\section{Introduction}

The tumor suppressor gene PTEN maps to chromosome 10q23.3, and encodes a dual specificity phosphatase. Germline mutations in PTEN are found in Cowden syndrome (CS), which is characterized by multiple hamartomas involving many organ systems as well as an increased risk of developing breast and thyroid cancers. Loss of heterozygosity (LOH) has been reported at this locus in around $40 \%$ of primary sporadic breast cancers, however only a very small fraction of these also have mutations in the remaining allele. Whether the loss of one PTEN allele is sufficient for tumorigenesis, or whether inactivation of the second allele might occur through epigenetic rather than mutational events has been open to question.

\section{Aims}

To study PTEN expression in primary human breast tumors using immunohistochemistry.

\section{Comments}

Findings of a high frequency of LOH at the PTEN gene locus in sporadic breast cancers, particularly in the more advanced stages of the disease, has led some investigators to assume an association with tumor progression. The very low rates of PTEN mutations in sporadic breast tumors have led others to conclude a lack of importance in breast pathogenesis. The data presented here on PTEN expression and mutation analysis appear to confirm both these observations, leading the authors to propose an epigenetic mechanism for allele inactivation. Attempts to correlate loss of PTEN expression with clinicopathological parameters need to be extended before the involvement of the PTEN pathway in breast carcinogenesis can be adequately assessed. 


\section{Methods}

Thirty-three unselected sporadic primary ductal breast carcinomas, which had previously been analyzed both for $\mathrm{LOH}$ at the 10q23 locus and PTEN mutations, were used in this study. A novel monoclonal antibody, $6 \mathrm{H} 2.1$, which was raised against the last $100 \mathrm{C}$-terminal amino acids of PTEN, was used in all immunohistochemical analyses. Biochemical evidence of antibody specificity was obtained by Western blot analysis of cell line protein lysates.

\section{Results}

In all of the normal tissue accompanying the primary breast cancers, the normal glandular epithelium showed positive staining with the $6 \mathrm{H} 2.1$ antibody. Of the 33 breast carcinoma samples, five (15\%) showed no PTEN immunoreactivity, although adjacent and enclosed non-neoplastic tissue stained positively. Of the 33 breast cancer specimens, $6(18 \%)$ stained weakly in comparison to normal tissue, while the remaining $22(66 \%)$ stained strongly positive. All of the five tumors showing no immunohistochemical evidence of PTEN expression also showed hemizygous PTEN deletion. None showed mutation of the remaining allele. Of the six carcinomas that had weak PTEN immunostaining, four showed LOH of the PTEN locus, whilst the other two were uninformative or showed retention of heterozygosity. Among the 22 carcinomas that showed immunohistochemical evidence of strong PTEN expression, 18 showed no $\mathrm{LOH}$. Of the four remaining tumors, three of these were found to retain heterozygosity at the $3^{\prime}$ end of the gene.

\section{Discussion}

Immunohistochemical analysis with a monoclonal antibody raised against PTEN showed 33\% of sporadic breast tumors with either decreased or no expression of the protein. This appeared to correlate with structural monoallelic deletion of the gene. Five samples with structural PTEN hemizygosity showed no immunoreactivity, and no intragenic PTEN mutations in the remaining allele either. The remaining allele may, however, be inactivated by an epigenetic phenomenon, such as hypermethylation of the promoter region and decreased protein synthesis or increased protein turnover. 


\section{References}

1. Perren A, Weng L-P, Boag AH, Ziebold U, Thakore K, Dahia PL, Komminoth P, Lees JA, Mulligan LM, Mutter GL, Eng C: Immunohistochemical evidence of loss of PTEN expression in primary ductal adenocarcinomas of the breast. Am J Pathol. 1999, 155: 1253-1260. 